\title{
Comparative study of crude and refined edible oils of sunflower and peanut
}

\author{
ESHTIAG IBRAHIM MOHAMMED, ELMUGDAD AHMED ALI" \\ College of Graduate Studies, Sudan University of Science and Technology, Shambat, Khartoum, Sudan. `email: elmugdadahmed-@ sustech.edu, \\ elmugdad@hotmail.com
}

Manuscript received: 21 November 2016. Revision accepted: 15 January 2017.

\begin{abstract}
Mohammed EI, Ali EA. 2017. Comparative study of crude and refined edible oils of sunflower and peanut. Biofarmasi J Nat Prod Biochem 15: 1-4. The objective of this study was to compare crude and refined edible oils of sunflower and peanut from their physical properties like color, moisture, density and refractive index, and chemical properties like peroxide value, zero fatty acid, acid value, saponifiable and non-saponifiable value. For example, after the refining process, the moisture content of sunflower oil was reduced from $0.07 \%$ to $0.02 \%$, and from $0.13 \%$ to $0.02 \%$ on peanut oil, and the peroxide value of sunflower oil was decreased from $13.94 \mathrm{meq} / \mathrm{kg}$ to $2.77 \mathrm{meq} / \mathrm{kg}$ and from $3.137 \mathrm{meq} / \mathrm{kg}$ to $0.2 \mathrm{meq} / \mathrm{kg}$ on peanut oil. Gas chromatographic applied on sunflower oil showed that stearic acid area percentage was decreased from 0.1 .8805 to 0.3510 after refining, and for peanut oil, it decreased from 11.1643 to 1.0281 after refining. This study showed marked differences in the physicochemical properties of sunflowers and those of peanuts. These properties of each crude oil were significantly changed when it was subjected to the refining process. GC determined fatty acid components of both crude and refined. The study showed striking differences in the crude and refined oils from sunflower and peanut types.
\end{abstract}

Keywords: Crude, edible, oils, peanut, refined, sunflower

\section{INTRODUCTION}

Oil and fats are water-insoluble substances of plants or animals, predominantly glyceryl esters of fatty acids or triglycerides. The word fat is generally used to refer to solid or, more precisely, semi-solid triglycerides at ordinary temperatures. In contrast, the word oil is used for liquid triglycerides under the same condition. No clear-cut distinction can be made between the two words, and both are used interchangeably except for important differences in solids and liquids (Bailey 1979).

The major sources of vegetable oils and fats are several hundred plants and animals that produce enough fats and oils to ensure processing into vegetable oils; however, few sources are numerically significant. Bovine, pig, and poultry are the main sources of commercial animal fat (Woodgate and van der Veen 2014). At the same time, the main source of vegetable oils is palm and palm kernel, soybean, rapeseed, sunflower seed, peanut, cottonseed, coconut, and olive (USDA 2009).

Sunflower (Helianthus annuus) oilseed comes from Argentina, where there are five major oilseed crops. The main fields of oilseed production are Eastern Europe, including Ukraine, Russia, Romania, Cina, and Argentine. It is also the major oilseed grown in southern France, Spain, and Turkey (FAOSTAT 2015). As its name suggests, the sunflower is well known for its heliotropism. The exact composition of sunflower seeds varies according to their origin. The un-decorated seed may contain $42-48 \%$ oil (Gunstone 2002; Phillips et al. 2005).

Groundnuts or peanuts (Arachis hypogaea) are annual herbaceous plants of leguminous branches originating from tropical America. The most important countries producing groundnut are China, India, Nigeria, the United States, and Sudan (FAOSTAT 2014). Groundnuts contain 40-55\% oil (Ozcanand Seven 2003; Phillips et al. 2005).

The objective of this study was to compare crude and refined vegetable oils of each sunflower and peanut for the physical properties such as color, moisture, density and refractive index, and chemical properties such as peroxide values, free fatty acids, acid values, saponifiable and nonsaponifiable number.

\section{MATERIALS AND METHODS}

\section{Materials}

The plant samples were collected from the Arab Sudanese Vegetable Oil Company (ASVOC), North Khartoum, Sudan, according to the standard sampling method to ensure that they are representative samples.

\section{Methods}

The methods are referred to by Kirk et al. (1991), D'Arcy and Hawes (2003), Ozcan and Seven (2003), Kenndler (2004), Shahidi (2005), Abitogun et al. (2008), AOCS (2009), and Hamm et al. (2013).

Color. This test was done by Digital Lovibond Tintometer, cell of 4 inches for crude oil, and Digital Lovibond PFX995 Tintometer, cell of 5.25 inches for refined oil. The glass cell was cleaned, dried, filled with the oil, and placed in the tintometer. The oil color was matched with the standard slides, i.e., red, yellow, and blue colors. The results were recorded. 
Moisture. Digital Mettle Toledo did this test, and $4 \mathrm{~g}$ of the sample was taken.

Density. The density of oil was determined by a pycnometer $(50 \mathrm{~mL})$. The pycnometer was first dried and weighed empty, and after being filled with sample and water, it was weighed to determine the weight of the sample and water. The volume of the sample to calculate the density of the oil sample, and at the end, calculated the density by the equation below:

$\mathrm{D}=\mathrm{W}$ (sample)/V (sample)

Where,

$\mathrm{D}=$ Density of oil

$\mathrm{W}$ (sample) =weight of sample. $\mathrm{g}$.

$\mathrm{V}$ (sample) $=$ volume of sample.

Refractive index. The refractive index was determined using a refractometer. A drop of oil was placed on the surface of the lower prism. The prisms were closed, and the mirror and light were adjusted until a dark borderline was visible on the cross wire. The refractive index was determined.

Peroxide value. $5 \mathrm{~g}$ of the sample were weighed in a flask, to which $25 \mathrm{~cm}^{3}$ of glacial acetic acid and chloroform (3:2) and $0.5 \mathrm{~cm}^{3}$ of potassium iodide were added. The flask was closed, shaken, and left to stand in the dark for 1 minute, preferably at $15-25 \mathrm{C}^{\circ}$. About $30 \mathrm{~cm}^{3}$ of water was added and titrated against $0.01 \mathrm{M}$ sod thiosulphate with vigorous stirring using the starch indicator to detect the endpoint, namely when the color of the solution changed from blue to colorless.

Free fatty acid. $7 \mathrm{~g}$ of the sample were weighed, to which $50 \mathrm{~cm}^{3}$ of neutral alcohol (ethanol 95\%) and $2 \mathrm{~cm}^{3}$ of phenolphthalein were added. The solution was titrated against $0.1 \mathrm{M}$ sodium hydroxide until its color changed to pink to indicate the endpoint.

Acid value. $25 \mathrm{~cm}^{3}$ diethyl ether was mixed with $25 \mathrm{~cm}^{3}$ alcohol and $1 \mathrm{~mL}$ of phenolphthalein solution (1\%) and carefully neutralized with $0.1 \mathrm{M}$ alkali. $1-10 \mathrm{~g}$ of the oil was dissolved and titrated against aqueous $0.1 \mathrm{M}$ sodium hydroxide while it was constantly shaken until a pink color which persisted for $15 \mathrm{sec}$, was obtained.

Saponifiable number. $2 \mathrm{~g}$ of the oil was weighed and poured into a conical flask, and $25 \mathrm{~cm}^{3}$ of the alcoholic potassium hydroxide solution was added. At the same time, it was being shaken frequently, and a reflux condenser was attached to the flask, which was heated in boiling water for $1 \mathrm{hr} .1 \mathrm{~mL}$ of phenolphthalein (1\%) solution was added. The hot excess of alkali was titrated with $0.5 \mathrm{M}$ hydrochloric acid (titration $=$ an $\mathrm{mL}$ ). A blank was carried out. Utmost care was taken during the titration. The titrated liquid in the sample flask was retained to determine the unsaponifiable matter.

Determination of non-saponifiable matter. After titrating the saponifiable number, the neutralized liquid was made alkaline again with $1 \mathrm{~cm}^{3}$ of aqueous $3 \mathrm{M}$ potassium hydroxide solution, transferred to a separator, and washed with water $(50 \mathrm{~mL}$ less the volume of $0.5 \mathrm{~N}$ hydrochloric acid used). The solution was extracted while still warm 3 times with $50 \mathrm{~cm}^{3}$ quantities of diethyl ether. Each ether was extracted into another separator containing $20 \mathrm{~cm}^{3}$ of water. After the third extract had been added, the combined ether extracts were shaken with the first $20 \mathrm{~cm}^{3}$ of washing water and then vigorously with the next two $20 \mathrm{~cm}^{3}$ quantities. The ether extract was washed twice with $20 \mathrm{~cm}^{3}$ of aqueous $0.5 \mathrm{M}$ potassium hydroxide solution and at least twice with $20 \mathrm{~cm}^{3}$ quantities of water until the washing water was no longer alkaline to phenolphthalein. The ether extract was poured into a weighed flask; the solvent was evaporated off, and the residue was dried at no more than $80{ }^{\circ} \mathrm{C}$ and weighed to constant weight.

Fatty acid analysis: [Injection port SPL1]. Injection Mode: Split. Temperature: $250^{\circ} \mathrm{C}$. Carrier Gas: N2/Air. Flow Control mode: Pressure. Pressure: 94.2kpa. Total Flow: $16.2 \mathrm{~mL} / \mathrm{min}$. Column Flow: $1.00 \mathrm{~mL} / \mathrm{min}$. Linear Velocity: $28.2 \mathrm{~cm} / \mathrm{sec}$. Purge Flow: $3.0 \mathrm{~mL} / \mathrm{min}$. [Column Oven] Initial Temperature: $100^{\circ} \mathrm{C}$. Equilibration Time: 0.0min. [Column Information] Column Name: DB-1. Serial Number: US6554753H. Film Thickness: 0.25um. Column Length: 30.0m. Inner Diameter: 0.25mm ID. Column Max Temperature: $350^{\circ} \mathrm{C}$. Description: non polar hydrocarbon/poly nuclear/aromatic/steroid. [Detector channel 1 FID1] Temperature: $300^{\circ} \mathrm{C}$ Signal Acquire: Yes. Sampling Rate: $40 \mathrm{msec}$. Stop Time: 60.0min. Delay Time:0.00min. Makeup Gas: N2/Air. Makeup Flow:30.0 $\mathrm{mL} / \mathrm{min}$. $\mathrm{H}_{2}$ Flow: $40.0 \mathrm{~mL} / \mathrm{min}$. Air Flow: $400.0 \mathrm{~mL} / \mathrm{min}$.

\section{RESULTS AND DISCUSSION}

\section{Physical tests}

The physical properties of crude and refined sunflower and edible peanut oils are in Table 1, including color, moisture, density, and refractive index.

\section{Chemical tests}

The chemical properties of crude and refined sunflower and edible peanut oils are in Table 2 , including peroxide value, free fatty acid, acid value, saponifiable number, and non-saponifiable matter.

Table 1. the Lovibond tintometer color of crude and refined oils of sunflower and peanut

\begin{tabular}{lcccccc}
\hline \multicolumn{1}{c}{ The oil } & Red & $\begin{array}{c}\text { Color } \\
\text { Blue }\end{array}$ & Yellow & Moisture & Density & Reactive index \\
\hline Crude sunflower & 4.5 & 0.9 & 25 & $0.07 \%$ & 0.9169 g.cm-3 & 1.468 \\
Refined sunflower & 1.0 & 0.0 & 5.0 & $0.02 \%$ & 0.9177 g.cm & 1.467 \\
Crude peanut & 3.6 & 0.8 & 25 & $0.13 \%$ & 0.9094 g.cm & 1.468 \\
Refined peanut & 1.0 & 0.0 & 4.2 & $0.02 \%$ & 0.9209 g.cm & 1.466 \\
\hline
\end{tabular}


Table 2. Peroxide free fatty acid values, acid value, saponifiable number, and non-saponifiable matter of crude and refined oils of sunflower and peanut

\begin{tabular}{lccccc}
\hline The oil & Peroxide value & Free Fatty acid & Acid value & Saponifiable number & $\begin{array}{c}\text { Non-saponifiable } \\
\text { matter }\end{array}$ \\
\hline Crude sunflower & $13.94 \mathrm{meq} / \mathrm{kg}$ & $1.27 \%$ & $2.4713 \mathrm{~g} / \mathrm{mol}$ & 192.1425 & 8 \\
Refined sunflower & $2.77 \mathrm{meq} / \mathrm{kg}$ & $0.04 \%$ & $0.2054 \mathrm{~g} / \mathrm{mol}$ & 186.5325 & 1.5 \\
Crude peanut & $3.137 \mathrm{meq} / \mathrm{kg}$ & $0.3615 \%$ & $1.8963 \mathrm{~g} / \mathrm{mol}$ & 190.74 & 4.5 \\
Refined peanut & $0.2 \mathrm{meq} / \mathrm{kg}$ & $0.08 \%$ & $0.1996 \mathrm{~g} / \mathrm{mol}$ & 189.3375 & 1 \\
\hline
\end{tabular}

Table 3. Fatty acid composition of crude and refined oils of sunflower and peanut

\begin{tabular}{|c|c|c|}
\hline Peak \# & Compound name & Area\% \\
\hline \multicolumn{3}{|c|}{ Crude sunflower oil } \\
\hline 1 & Undecanoicacid & 0.3963 \\
\hline 2 & Tridecanoicacid & 2.7035 \\
\hline 3 & Myristicacid & 0.4355 \\
\hline 4 & Cis-10-Pentadecenoic Acid & 20.6702 \\
\hline 5 & PalmitoleicAcid & 67.8046 \\
\hline 6 & Linolelaidic Acid & 0.3610 \\
\hline 7 & Elaidic Acid & 0.9562 \\
\hline 8 & Stearic Acid & 1.8805 \\
\hline 9 & Arachidonic Acid & 3.5917 \\
\hline 10 & ErucicAcid & 1.0078 \\
\hline 11 & Tricosanoic acid & 0.1927 \\
\hline Total & & 100.0000 \\
\hline \multicolumn{3}{|c|}{ Refined sunflower oil } \\
\hline 1 & Undecanoic acid ME & 0.0779 \\
\hline 2 & Tri decanoic acid $\mathrm{M}$ & 0.5825 \\
\hline 3 & Myristic acid M.E & 0.1396 \\
\hline 4 & Cis-10-pentadeceno & 7.9634 \\
\hline 5 & Palmitoleic acid M.E & 0.1993 \\
\hline 6 & Palmitic acid M.E & 89.6607 \\
\hline 7 & Heptadecanioc acid & 0.2822 \\
\hline 8 & Oleic acid M.E & 0.0087 \\
\hline 9 & Stearic acid M.E & 0.3510 \\
\hline 10 & Cis-8,11,14-Eicosath & 0.918 \\
\hline 11 & Arachidonic acid M & 0.5398 \\
\hline 12 & Erucic acid M.E & 0.1030 \\
\hline Total & & 100.0000 \\
\hline \multicolumn{3}{|c|}{ Crude peanut oil } \\
\hline 1 & Undecanoic acid ME & 0.2243 \\
\hline 2 & Tri decanoic acid $\mathrm{M}$ & 0.8616 \\
\hline 3 & Cis-10-pentadeceno & 59.3641 \\
\hline 4 & Palmitoleic acid M.E & 0.7531 \\
\hline 5 & Linolelaidic acid M & 1.1275 \\
\hline 6 & Elaidic acid M.E & 2.3556 \\
\hline 7 & Stearic acid M.E & 11.1643 \\
\hline 8 & Cis-8,11,14-Eicosath & 0.2619 \\
\hline 9 & Cis-11-Eicosath & 16.6382 \\
\hline 10 & Heptadecanioc acid & 0.1342 \\
\hline 11 & Erucic acid M.E & 6.1132 \\
\hline 12 & Tricosanoic acid M.E. & 1.0020 \\
\hline Total & & 100.0000 \\
\hline \multicolumn{3}{|c|}{ Refined peanut oil } \\
\hline 1 & Tricosanoic acid M.E. & 0.5157 \\
\hline 2 & Myristic acid M.E & 0.1617 \\
\hline 3 & Cis-10-pentadecenoic acid M.E & 12.3999 \\
\hline 4 & Palmitoleic acid M.E & 0.4664 \\
\hline 5 & Palmitic acid M.E & 83.0663 \\
\hline 6 & Linolelaidic acid M.E & 0.5223 \\
\hline 7 & Stearic acid M.E & 1.0281 \\
\hline 8 & Cis-11-EicosnoicM.E. Cis-11,14,1- & 1.4202 \\
\hline 9 & Erucic acid M.E & 0.4194 \\
\hline Total & & 100.0000 \\
\hline
\end{tabular}

The fatty acid composition of crude and refined oils of sunflower and peanut can be seen in Table 3 .

\section{Discussion}

The physicochemical properties of crude and refined oils of sunflower and peanut were studied. The physical property of crude and refined sunflower oil is as follows: Bleaching the color of the sunflower oil was clearly noticed when the crude product was refined. The Lovibond reading was decreased from 4.5 to 1.0 for red, from 0.9 to 0.0 for blue, and from 25 to 5 for yellow. Similarly, the moisture content was reduced from $0.07 \%$ to $0.02 \%$. Likewise, the refractive index decreased from 1.468 to 1.467 . The density, however, was slightly increased from 0.9169 g.cm ${ }^{3}$ to 0.9177 g.cm ${ }^{-3}$.

The physical properties of crude and refined peanut oil are as follows: bleaching of the color of the oil peanut was clearly noticed when the crude product was refined. The Lovibond reading was decreased from 3.6 to 1.0 for red, from 0.8 to 0.0 for blue, and from 25 to 4.2 for yellow. Similarly, the moisture content was reduced from $0.13 \%$ to $0.02 \%$. Likewise, the refractive index decreased from 1.468 to 1.466 . The density, however, was high increased from 0.909 g.cm ${ }^{-3}$ to 0.920 g.cm $\mathrm{cm}^{-3}$.

The chemical properties of crude and refined sunflower oil: The peroxide value decreased from $13.94 \mathrm{meq} / \mathrm{kg}$ to $2.77 \mathrm{meq} / \mathrm{kg}$. Similarly, the free fatty acid was decreased from $1.27 \%$ to $0.04 \%$. The acid value decreased from 2.4713 to 0.2054 . The saponifiable number decreased from 192.1425 to 186.5325 , and the non-saponifiable matter decreased from 8 to 1.5 .

The chemical properties of crude and refined peanut oil: The peroxide value was decreased from $3.137 \mathrm{meq} / \mathrm{kg}$ to $0.2 \mathrm{meq} / \mathrm{kg}$. Similarly, the free fatty acid was decreased from $0.3615 \%$ to $0.08 \%$. The acid value decreased from 1.8963 to 0.1996 . The saponifiable number decreased from 190.74 to 189.3375 , and the non-saponifiable matter decreased from 4.5 to 1 .

The fatty acid of crude sunflower oil detected were palmitoleic acid, cis-10-pentadecenoic acid, arachidonic acid, tridecanoic acid, stearic acid, erucic acid, elaidic acid, myristic acid, undecanoic acid, linolelaidic acid and tricosanoic acid and their area\%. The area \% were $67.8046 \%, 20.6702 \%, 3.5917 \%, 2.7035 \%, 1.8805 \%$, $1.0078 \%, 0.9562 \%, 0.4355 \%, 0.3963 \%, 0.3610 \%$, and $0.1927 \%$ respectively.

The fatty acid of refined sunflower oil which were detected were palmitoleic acid, cis-10-pentadecenoic acid, arachidonic acid, tridecanoic acid, stearic acid, erucic acid, 
myristic acid, undecanoic acid, palmitic acid, heptadecanoic acid, oleic acid and cis-8, 11, 14-eicosatic acid and their area \%. The area \% were $0.4775 \%$, $20.1220 \%, \quad 1.6902 \%, \quad 2.0329 \%, \quad 0.7481 \%, \quad 0.3366 \%$, $0.3158 \%, 0.2397 \%, 72.1860 \%, 1.29886 \%, 0.2613 \%$ and $0.2914 \%$ respectively.

In crude sunflower oil, linoleic, linolenic, and oleic acid were not found, and in refined one, linoleic and linolenic acid was not found. In crude sunflower oil, the contribution of palmitoleic acid, cis-10-pentadecenoic acid, arachidonic acid, tridecanoic acid, stearic acid, erucic acid, elaidic acid, myristic acid, undecanoic acid, linolelaidic acid, and tricosanoic acid was found to be high in comparison with refined one.

The fatty acid of crude peanut oil which were detected were palmitolic acid, cis- 10-pentadecenoic acid, tridecanoic acid, stearic acid, erucic acid, elaidic acid, undecanoic acid, linolelaidic acid, tricosanoic acid, cis-8, 11, 14-eicosatic acid, cis- 11-eicosenoic acid and heneicosanoic acid. The area \% were $1.6999 \%, 50.0597 \%$, $2.3096 \%, \quad 11.3800 \%, 8.9181 \%, \quad 2.5748 \%, \quad 0.4202 \%$, $1.0842 \%, 1.1639 \%, 0.4105 \%, 19.7005 \%$ and $0.2784 \%$ respectively.

The fatty acid of refined peanut oil which were detected were palmitoleic acid, cis- 10-pentadecenoic acid, tridecanoic acid, stearic acid, erucic acid, linoleic acid, cis11- eicosenoic acid, myristic acid, and palmitic acid. The area $\%$ were $0.4664 \%, 12.3999 \%, 0.5157 \%, 1.0281 \%$, $0.4194 \%, 0.5223 \%, 1.4202 \%, 0.1617 \%$ and $83.0663 \%$ respectively.

In crude peanut oil, myristic, palmitic, oleic, linoleic, linolenic, arachidic, gadoleic, and behenic acids were not found; in refined one, oleic, linolenic, arachidic, gadoleic, and behenic acids were not found. In crude peanut oil, the contribution of tridecanoic, cis-10-pentadecenoic, palmitoleic, stearic, cis-11-eicosenoic, and erucic acid was found to be high in comparison with refined ones. The sample may be forged as long as the crude and refined peanut sample shows no arachidic acid, and peanut oil is famous for its arachidic acid component.

\section{REFERENCES}

Abitogun A, Omosheyin A, Oloye D, Alademehin O. 2008. Extraction and characterirization of crude sunflower oil. Internet J Nutr Wellness 8 (2): 1-5. https://print.ispub.com/api/0/ispub-article/4298

AOCS. 2009. Official Methods and Recommended Practices of the American Oil Chemists' Society. 6th ed. American Oil Chemists' Society, Champaign, Illinois, USA

D'Arcy BR, Hawes G. 2003. Chemical Food Analysis A Practical Manual. University of Queensland, Brisbane.

FAOSTAT. 2014. FAOSTAT, Food and Agricultural Organization of the United Nations, Statistics Division. FAO, Rome.

FAOSTAT. 2015. UN Food and Agriculture Organization Corporate Statistical Database (FAOSTAT). FAO, Rome.

Gunstone E. 2002. Sunflower seed and its products. Inform 13: 159-163.

Hamm W, Hamilton RJ, Calliauw G (eds). 2013. Edible Oil Processing, 2nd ed. Wiley-Blackwell, New York.

Kenndler E. 2004. Introduction to Chromatography. University of Vienna, Vienna.

Kirk RS, Sawyer R, Egan H. 1991. Pearson's Composition and Analysis of Foods. 9 Sub ed. Longman Group, Harlow, UK.

Ozcan M, Seven S. 2003. Physical and chemical analysis and fatty acid composition of peanut, peanut oil and peanut butter from ÇOM and NC-7 cultivars. Grasas y Aceites 54 (1): 12-18.

Phillips KM, Ruggio DM, Ashraf-Khorassani M. 2005. Phytosterol composition of nuts and seeds commonly consumed in the United States. J Agric Food Chem 53 (24): 9436-9445.

Shahidi F (ed.). 2005. Bailey's Industrial Oil and Fat Products. 6th ed. John Wiley and Sons, New York.

USDA 2009. Oilseeds: World Market and Trade. FOP 1. USDA, Washington, DC.

Woodgate SL, van der Veen JT. 2014. Fats and Oils - Animal Based. In: Clark S, Jung S, Lamsal B (eds). Food Processing: Principles and Applications, 2nd ed. John Wiley \& Sons, Ltd. New York. 